\title{
Compreensões de licenciand@s em Química acerca do Pensamento Crítico: um possível horizonte interpretativo
}

Vivian dos Santos Calixto viviancalixto89@gmail.com 1-Universidade Federal da Grande
Dourados (UFGD), Dourados, Mato Grosso do Sul, Brasil 2-Universidade Estadual de Maringá (UEM), Maringá, Paraná, Brasil

Ananda Jacqueline Bordoni bordoni.ananda@gmail.com Universidade Estadual de Maringá (UEM), Maringá, Paraná, Brasil

\section{Danieli Azanha Gazzoni}

Takahashi

dany gazzoni@hotmail.com Universidade Estadual de Maringá (UEM), Maringá, Paraná, Brasil

Neide Maria Michellan Kiouranis nmmkiouranis@gmail.com

Universidade Estadual de Maringá (UEM) Maringá, Paraná, Brasil

Marcelo Pimentel da Silveira martzelops@gmail.com

Universidade Estadual de Maringá (UEM) Maringá, Paraná, Brasil

\section{RESUMO}

Objetivamos por meio deste trabalho compreender como professores/as em formação concebem o conceito de pensamento crítico. Para tanto, foram analisadas escritas produzidas em um componente curricular com carga horária integralmente destinada a Prática como Componente Curricular. As mesmas constituem o primeiro movimento de escrita d@s licenciand@s no Portfólio, instrumento de avaliação do componente anteriormente citado. Foram elaboradas dezenove escritas e analisadas partindo dos pressupostos da Análise Textual Discursiva. Diante da análise dos textos emergiu a categoria final intitulada "O perfil do pensador crítico: potência no processo de desvelamento da realidade", na qual é atribuído ao pensador crítico a capacidade de problematizar o contexto em que se insere por meio de olhar crítico e atento. Observando com racionalidade, buscando constantemente por conhecimento e desconstruindo verdades estáticas.

PALAVRAS-CHAVE: Prática como Componente Curricular. Pensamento crítico. Formação de professores. 


\section{INTRODUÇÃO}

Nos dias de hoje, o desenvolvimento das capacidades de pensamento crítico se torna cada vez mais importante, visto que há o reconhecimento de que este seja essencial para viver em sociedade (TENREIRO-VIEIRA, 2000). A habilidade de pensar criticamente sempre foi importante em nossa sociedade, notadamente, a partir dos séculos XX e XXI, com a necessidade de formar cidadãos com capacidades de tomarem decisões coerentes, uma vez que delas dependem, a manutenção da vida no planeta Terra (HALPERN, 1989).

Afirma-se ainda a necessidade de promover as capacidades de pensamento dos alunos, no contexto da educação em ciência, pois vive-se num mundo onde, cada vez mais, os cidadãos são chamados a intervir e a tomar posição sobre questões públicas, nomeadamente, sobre as implicações sociais da ciência e da tecnologia. Efectivamente, todos os estudantes de ciências serão elementos integrantes de uma sociedade e, enquanto cidadãos, tornam-se responsáveis pelos riscos e benefícios do conhecimento, dos produtos e dos sistemas científicos e tecnológicos. (TENREIRO-VIEIRA, 2004, p.2).

Sendo assim, emerge a necessidade de formarmos cidadãos conscientes, cuja as decisões possam tomar proporções que venham a afetar tanto a sua vida, como a da sociedade em que vivem. Quando pensamos no formato de ensino que temos hoje, é possível ver como nossos alunos são cobrados a tomarem decisões e analisarem argumentos, para, assim conseguirem responder problemas que thes são impostos, mas estes alunos, na maioria das vezes não são ensinados a como fazer isso (HALPERN, 1989).

Ao pensarmos na formação dos professores, estes muitas vezes não estão sendo formados com esse propósito, ocasionando a necessidade de formarmos professores que saibam usar suas capacidades de pensamento crítico (VIEIRA e TENREIRO-VIEIRA, 2005), uma vez que os alunos só terão participação ativa, interesse pessoal e envolvimento em diferentes situações cotidianas, se o professor conceber e propor estratégias de ensino que oriente esse propósito.

A formação de professores vem sendo intensamente discutida, uma vez que busca identificar os aspectos que compõem a articulação entre teoria e prática. Investir em tendências inovadoras de ensino e aprendizagem, que contribuam com uma formação mais significativa, no que diz respeito a um desenvolvimento profissional fortemente embasado em questionamentos acerca das exigências curriculares, tanto científicas como sociais, implica também em ações promotoras de pensamento crítico.

É fundamental que cursos de licenciatura apresentem um currículo que permita o desenvolvimento de diferentes estratégias de ensino e de aprendizagem, com particular ênfase na promoção das capacidades de pensamento crítico. Como discute Tenreiro-Vieira (2000, p. 21),

"Os currículos devem legitimar o ensino das capacidades de Pensamento Crítico. Os materiais curriculares disponíveis devem fornecer sugestões concretas e claras sobre o modo como se pode concretizar o ensino das capacidades de Pensamento Crítico".

Desta forma, a inserção do ensino do pensamento crítico voltado para os componentes curriculares das Ciências da Natureza, se mostra de fundamental 
importância, do mesmo modo que se articula com outras estratégias, perpassando os diferentes componentes do currículo. Szabo e Schwartz (2011) afirmam que a promoção das capacidades de pensamento crítico é essencial para a formação, e deveria fazer parte dos programas de formação de professores. Assim, pois estes futuros professores terão melhor embasamento para desenvolverem algumas capacidades, como análise e síntese de materiais o que os tornam mais reflexivos, além de aprenderem a pensar criticamente.

Ao considerarmos que termos como "crítico" e "pensamento crítico" são comumente utilizados pelos licenciand@s nos componentes curriculares, na interface pedagógica dos cursos de licenciatura em Química, neste trabalho, buscou-se compreender as concepções expressas por licenciand@s em Química acerca da definição de pensamento crítico. Para que isso fosse possível, buscamos a partir das escritas de seus Portfólios, delinear suas características e tecer algumas possíveis contribuições para o Ensino de Química.

O processo de análise nos proporcionou vislumbrar um possível horizonte interpretativo, emergente da intensa impregnação para com as escritas dos licenciand@s sobre o tema foco de discussão. A noção de horizonte interpretativo é decorrente da discussão tecida por Souza e Galiazzi (2016, p.46), quando apresentam a compreensão emergente do processo de textualização decorrente da Análise Textual Discursiva (ATD), nas palavras dos autores: "São os horizontes interpretativos do pesquisador que limitam ou ampliam o reconhecimento daquilo que permanece, do que é identificado como essencial à compreensão do fenômeno que é sempre limitada por quem interpreta".

\section{PENSAMENTO CRÍTICO E FORMAÇÃO DE PROFESSORES/AS: UMA ARTICULAÇÃO NECESSÁRIA}

Quando falamos em Formação, devemos levar em consideração o fato de estarmos tratando de um assunto complexo, pois poucos são os consensos existentes englobando às teorias e às dimensões relevantes para a análise. Portanto, segundo Soares e Cunha (2010), formação não deve ser confundida com educação, ensino ou treino, uma vez que envolve uma dimensão pessoal, humana e global. Podemos definir a formação de professores da seguinte forma:

\footnotetext{
[...] a área de conhecimentos, investigação e de propostas teóricas e práticas que, no âmbito da Didática e da Organização Escolar, estuda os processos através dos quais os professores - em formação ou em exercício - se implicam individualmente ou em equipe, em experiências de aprendizagem através das quais adquirem ou melhoram os seus conhecimentos, competências $e$ disposições, $e$ que thes permitem intervir profissionalmente no desenvolvimento do seu ensino, do currículo e da escola, com o objetivo de melhorar a qualidade da educação que os alunos recebem. (GARCÍA, 1999, p. 26).
}

Ao propormos melhorias no ensino e na formação dos professores, devemos partir da formação inicial, pois é neste momento que os futuros profissionais da educação começam a ser instrumentalizados. Segundo Paredes e Guimarães (2012), a primeira necessidade formativa está relacionada ao conhecimento do conteúdo a ser ensinado, a falta do mesmo gera insegurança ao lecionar, porém, 
esta não é a única necessidade formativa, o ser professor vai muito além de saber o conteúdo.

Existe uma grande rejeição com os cursos de licenciatura, que em muitas situações, é proveniente da indiferença e da desvalorização que ocorre nas instituições formadoras, uma vez que a estrutura curricular nem sempre é compatível para uma boa formação do professor, deixando evidente o descaso com a profissão "professor", desde a sua formação inicial. Segundo Almeida e Biajone (2007), os cursos que objetivam a formação inicial de professores devem promover a vivência de novas práticas e novos instrumentos de formação, desde estudos de casos e práticas, estágio com maior tempo de duração, problematização e a análise reflexiva.

Um dos grandes desafios dos cursos de formação inicial é estabelecer uma interação efetiva entre o acadêmico e o ambiente escolar de maneira ativa (ALMEIDA et al., 2010), bem como outras práticas. Logo, "A formação implica uma ação profunda sobre a pessoa, agindo tanto sobre os saberes, à semelhança do ensino, como sobre as atitudes e os valores, tal como a educação" (RODRIGUES, 2006, p. 27), resultando no desenvolvimento pessoal e profissional. "É através da interformação que os sujeitos - nesse caso os professores - podem encontrar contextos de aprendizagem que favoreçam a procura de metas de aperfeiçoamento pessoal e profissional" (GARCÍA, 1999, p. 22).

Compreender a prática dos professores requer buscar novos referenciais teóricos, estudos que contenham informações sobre os saberes pedagógicos e epistemológicos relacionados aos conteúdos que compõem a prática docente. Borges e Tardif (2001), destacam que no quadro atual da pesquisa, busca-se compreender a profissão docente bem como os processos de profissionalização, partindo da visão que os próprios sujeitos apresentam.

Schulman (1986), defende a valorização do saber docente mediante o conteúdo a ser ensinado, a recuperação do paradigma, o conteúdo de ensino e aprendizagem. No decorrer da formação inicial, deve-se explorar os conhecimentos que os professores apresentam mediante o conteúdo, bem como os conhecimentos didáticos, objetivando transformar o ensino.

Desta forma, um dos referenciais teóricos que acreditamos ser importante abordar na formação inicial, está relacionado a discussão sobre o conceito de pensamento crítico. Vivemos em uma sociedade onde cada vez mais somos cobrados a tomarmos decisões, e em distintos documentos e leis emerge com maior frequência a necessidade de formarmos cidadãos críticos em sociedade. Mas, para que as capacidades de pensamento crítico sejam promovidas é necessário que ocorram mudanças no processo de ensino e aprendizagem, consequentemente na formação inicial dos professores (HALPERN, 1998).

Como o ensino do pensamento crítico é intencional, racional e direcionado para uma meta, para que seja possível a promoção das capacidades de pensamento crítico dos alunos, é essencial intervir na formação dos professores (TENREIRO-VIEIRA, 2000). Lembrando que ao falarmos do ensino de pensamento crítico, não nos referimos somente ao uso de suas capacidades.

O professor também deve estar preparado para o ensino dos conteúdos propostos, tendo início na formação destes. Para abordarmos o porquê da importância do ensino do pensamento crítico na formação inicial de professores, 
emerge a necessidade de discutirmos qual o seu significado e como este vai articular-se com o ensino.

O pensamento crítico se manifesta na forma do pensar, tomar decisões e resolver problemas de forma crítica, e teve o seu ápice nos séculos XX e XXI. Nesse contexto, diferentes pesquisadores começaram a pesquisar essa forma de pensar, dando início assim a diferentes teorias referentes ao pensamento crítico, como o desenvolvimento de suas capacidades (TENREIRO-VIEIRA; VIEIRA, 2001). Tornando-se importante as discussões de algumas definições de teóricos influentes da área de ensino de pensamento crítico.

Começando pela teórica Diane F. Halpern (1989), que discute acerca do pensamento e o conhecimento, fazendo uma introdução aos estudos de pensamento crítico. Para a autora, o termo pensamento crítico pode ser usado com o intuito de descrever um pensamento proposital, ou que tenha um objetivo ou fundamento, sendo o tipo de pensamento que normalmente está ligado a resolução de problemas, cálculos de probabilidade, assim como, tomada de decisões (HALPERN, 1989).

A autora também discute que muitas vezes a palavra "crítico" é usada com um tom pejorativo, ou seja, transmitindo um sentido negativo. Mas deveríamos pensar que o termo crítico vem de avaliação, podendo ser essa tanto construtiva, quanto negativa, objetivando fornecer um feedback útil e preciso. Quando conseguimos avaliar os nossos processos de pensamento, as decisões tomadas e a resolução de problemas, podemos dizer que estamos pensando criticamente (HALPERN, 1989).

Halpern (1998) complementa o discurso proposto anteriormente dizendo que o termo pensamento crítico, se refere ao uso das habilidades e estratégias cognitivas, aumentando a probabilidade de se obter um resultado mais desejável a longo prazo, diferente dos que não pensam criticamente. Podemos dizer que ao pensar criticamente, faz-se de uma forma apropriada e consciente, ou seja, os que pensam dessa forma estão predispostos a pensar criticamente.

Com isso, a autora discute que os nossos sonhos ou pensamentos quando não estão dirigidos a um objetivo específico, não podem ser categorizados como pensamento crítico, assim como, as decisões e hábitos rotineiros que temos, pois mesmo sendo direcionados a um objetivo, envolvem pouca ou nenhuma avaliação, esses tipos de pensamentos, podem ser categorizados como pensamentos não dirigidos (HALPERN, 1989). Em resumo, podemos dizer que para a autora, o termo pensamento crítico está relacionado a avaliação dos processos de pensamento, como avaliação e tomada de decisão, que são pensamentos que fazemos conscientemente.

Outro teórico influente na área de ensino de pensamento crítico, é Richard Paul, que em parceria com Linda Elder, discutem em sua obra a essência do pensamento crítico, podendo ser resumida como a arte de pensar sobre o pensamento, seja ele de forma que possa identificar os pontos fortes e fracos ou até então, conseguir modificá-los (PAUL; ELDER, 2008).

Os autores, assim como Halpern, discutem o pensamento crítico como uma forma de avaliação, ou seja, é uma forma de analisar e avaliar o pensamento com o intuito de poder melhorá-lo (PAUL; ELDER, 2006). Tenreiro-Vieira e Vieira (2000) discutem que Paul estabelece uma distinção entre o pensamento crítico em dois 
sentidos, sendo o primeiro o pensamento crítico no sentido fraco, que podemos caracterizar como um pensar monológico, conduzido por um único ponto de vista. E o segundo, o pensamento crítico no sentido forte, que pode ser caracterizado como o pensamento dialógico, apresentando mais de um ponto de vista.

Sendo Robert H. Ennis (TENREIRO-VIEIRA; VIEIRA, 2001), o teórico mais influente que discute o pensamento crítico, mais especificamente, voltado para o campo educacional, assim como, o ensino das capacidades deste pensamento. Ennis (1996) discute a definição do termo pensamento crítico, como sendo o termo que usamos quando damos significado a uma atividade prática e reflexiva.

Para este pesquisador, podemos classificar o pensamento em cinco termoschave para definir o pensamento crítico, sendo estes: reflexivo, sensato, prático, crença e ação. Ou seja, para ele, o pensamento crítico é uma forma de pensar racionalmente, onde há a reflexão e esteja focado em como agir e no que decidir (TENREIRO-VIEIRA; VIEIRA, 2001). No âmbito do ensino de ciências, a definição de pensamento crítico de Ennis é a mais utilizada (VIEIRA; TENREIRO-VIEIRA, 2015).

Vieira e Tenreiro-Vieira, são dois importantes pesquisadores que investigam o ensino de pensamento crítico. Esses autores adaptaram a definição de Ennis (1996) para o termo pensamento crítico, "[...] pensamento crítico é reflexivo e que está centrado na avaliação. Racionalidade, reflexão e avaliação constituem, pois características chave do pensamento crítico" (TENREIRO-VIEIRA; VIEIRA, 2001, p.29). Na perspectiva deste estudo adotaremos os pressupostos adaptados de Ennis (1996) por estes autores, uma vez que os consideramos adequados e pertinentes ao contexto educacional.

Como se depreende dessa reflexão, o pensamento crítico envolve racionalidade, reflexão e avaliação, sendo assim, se o professor não for formado com esse objetivo, não será possível o ensino das capacidades de pensamento crítico em suas aulas. Nesse sentido, parece impossível admitir que a capacidade de pensar não seja necessária. Tradicionalmente, nossas escolas exigem que os alunos saibam tomar decisões, analisar problemas e resolvê-los, mas na maioria das vezes não são ensinados sobre como fazer (HALPERN, 1989).

\section{ASPECTOS METODOLÓGICOS}

Este trabalho assume uma abordagem qualitativa, com foco de discussão na formação de professores de química. Nesse sentido, nos ancoramos na pesquisaação e na perspectiva histórico-cultural da pesquisa na formação de professores que "implica perceber o objeto em movimento[...] faz-se necessário que a análise da aprendizagem se realize no contexto das inter-relações entre situações e sujeitos[...]" (ARAUJO; MOURA, 2008, p. 91).

Segundo Araujo; Moura (2008, p.91-92):

Defender uma proposta de trabalho condizente com uma abordagem de pesquisa qualitativa, na perspectiva da pesquisa-ação, implica considerarmos dois princípios. Um é o de pensar quais ações e instrumentos são necessários para que se garanta a participação efetiva - no processo e no produtor - de todos os segmentos envolvidos. [...] Outro princípio está em compreender as relações entre a objetividade do conteúdo dos conceitos e as teorias da ciência, em sua dimensão de movimento e mutabilidade. 
Fundamentando-nos pressupostos apresentados, a constituição do material empírico orientou-se essencialmente pela primeira escrita de Portfólios produzidos por licenciand@s em um componente curricular, com carga horária integral destinada a Prática como Componente Curricular, apresentando discussões centradas nas Teorias da Aprendizagem, de um curso de Química de uma Universidade da região Centro-Oeste.

A produção do Portfólio configura-se como um instrumento de avaliação, contínua e formativa ao longo do componente anteriormente citado. O Portfólio vem sendo utilizado na formação de professores com certa frequência, porém precisamos nos atentar para suas características e objetivos. Villas Boas (2004, p.39) apresenta a seguinte compreensão sobre o mesmo:

Percebe-se, então que o portfólio é mais do que uma coleção de trabalhos do aluno. Não é uma pasta onde se arquivam textos. A seleção dos trabalhos a serem incluídos é feita por meio de auto-avaliação crítica e cuidadosa, que envolve o julgamento da qualidade de produção e das estratégias de aprendizagem utilizadas. A compreensão individual do que constitui qualidade em um determinado contexto e dos processos de aprendizagem envolvidos é desenvolvida pelos alunos desde o início de suas experiências escolares. Essa compreensão pode ser facilitada pela interação com colegas e professores e pela reflexão em vários momentos: a) de trabalho individual e em equipe; b) durante a apresentação dos portfólios pelos colegas; c) por meio do confronto da produção com os objetivos descritores da avaliação.

O Portfólio, na sua primeira escrita foi orientado a partir dos seguintes questionamentos: O que é ser professor de Química; O que é pensamento crítico; Como promover o pensamento crítico em sala de aula. Neste trabalho nos centramos na análise do que é proposto no segundo questionamento: o que é pensamento crítico.

A turma apresentava um quantitativo de alunos que girava em torno de trinta, no entanto, apenas vinte e cinco realizaram a primeira escrita no Portfólio, sendo que apenas dezenove desenvolveram em sua escrita o foco do segundo questionamento orientador, o que é pensamento crítico.

A análise das escritas dos Portfólios orientou-se nos pressupostos da Análise Textual Discursiva proposta por Moraes e Galiazzi (2011). A mesma ancora-se nos pressupostos da fenomenologia e da hermenêutica, buscando descrever e interpretar com intensidade os fenômenos, foco de estudo. Basicamente estrutura-se em três movimentos: a) desmontagem dos textos/unitarização; b) estabelecimento de relações/categorização e; c) captando o novo emergente/metatexto (MORAES; GALIAZZI, 2011).

No primeiro movimento o pesquisador trabalha intensamente com o texto, realizando uma leitura flutuante, buscando observar o que constitui a essência do texto. Essa leitura exploratória, ainda é muito superficial e não produz grandes intervenções do pesquisador sobre o texto. Em um segundo momento começam a ser sinalizadas as unidades de significado em cada texto, no nosso caso, para cada escrita do Portfólio, d@s dezenove licenciand@s, buscamos nos centrar no que era expresso acerca do que os mesmos compreendiam como pensamento crítico. Desse processo surgem as unidades de significado, em nossa análise constituímos dezenove unidades de significado, que posteriormente orientaram o processo de categorização. 
Começamos no segundo movimento a nos distanciar do texto como um todo, e passamos a trabalhar diretamente com as unidades de significado. Nesse sentido, para cada unidade de significado atribuem-se palavras-chave, sendo estas provenientes das unidades de significados, ou seja, ainda lidamos diretamente com as falas dos licenciand@s.

Depois de atribuirmos as palavras-chave para cada unidade de significado, elaboramos títulos para as mesmas, sendo estes a partir das palavras-chave. Ao observarmos apenas os títulos, começamos o processo de categorização. Ou seja, para cada título uma categoria inicial, quando a temática parecia ser próxima atribuímos a mesma codificação de categoria inicial. Após a categorização inicial, observando os títulos que constituíam a categoria inicial, e com isso organizamos um argumento, ou seja, um argumento para cada categoria inicial.

Posteriormente, analisando os argumentos das categorias iniciais, buscamos possibilidades de aproximação, emergindo as categorias intermediárias. Ao observar os argumentos que constituem as categorias intermediárias selecionamos palavras-chave, títulos e argumentos novamente. Observando mais uma vez os argumentos das categorias intermediárias e buscando aproximações emergiram as categorias finais.

O terceiro movimento configura-se pela escrita do metatexto, esse movimento encontra-se imbricado ao segundo, visto que nesse processo as unidades de significado constituem discussões das categorias iniciais, que por sua vez constituem as discussões das categorias intermediárias que constituem as discussões das categorias finais. No nosso processo de análise tínhamos dezenove unidades de significado que se organizaram em oito categorias iniciais, posteriormente reagrupadas em quatro categorias intermediárias que por sua vez se organizaram em uma categoria final.

O processo, simplificado, de categorização pode ser observado no Quadro 1 a seguir:

Quadro 1 - Processo de categorização das escritas do Portfólio

\begin{tabular}{|c|c|c|c|}
\hline & Categorias Inicias & $\begin{array}{l}\text { Categorias } \\
\text { Intermediárias }\end{array}$ & Categoria Final \\
\hline$A(3)$ & $\begin{array}{l}\text { O pensamento crítico } \\
\text { promove o desvelamento } \\
\text { do olhar do sujeito } \\
\text { proporcionando-o } \\
\text { compreender o real } \\
\text { sentido do contexto em } \\
\text { que está imerso. }\end{array}$ & $\begin{array}{l}(A+E)-A \text { observação } \\
\text { atenta e crítica promove ao } \\
\text { pensador crítico } \\
\text { desvelamento do contexto } \\
\text { em que está imerso, }\end{array}$ & $\left\{\begin{array}{l}\text { O pensador crítico } \\
\text { problematiza o contexto em } \\
\text { que se insere por meio de } \\
\text { olhar crítico e atento. } \\
\text { Observando } \\
\text { racionalidade, }\end{array}\right.$ \\
\hline$E(3)$ & $\begin{array}{lr}\text { O pensamento } & \text { crítico } \\
\text { oportuniza ao } & \text { sujeito } \\
\text { problematizar } & \text { seu } \\
\text { entorno social, por meio } \\
\text { da observação atenta e } \\
\text { crítica. }\end{array}$ & $\begin{array}{l}\text { apresenta-se } \\
\text { explicitamente em sua } \\
\text { realidade. (6) }\end{array}$ & $\begin{array}{lr}\text { constantemente } & \text { por } \\
\text { conhecimento } & \text { e } \\
\text { desconstruindo } & \text { verdades } \\
\text { estáticas.(19) } & \end{array}$ \\
\hline
\end{tabular}




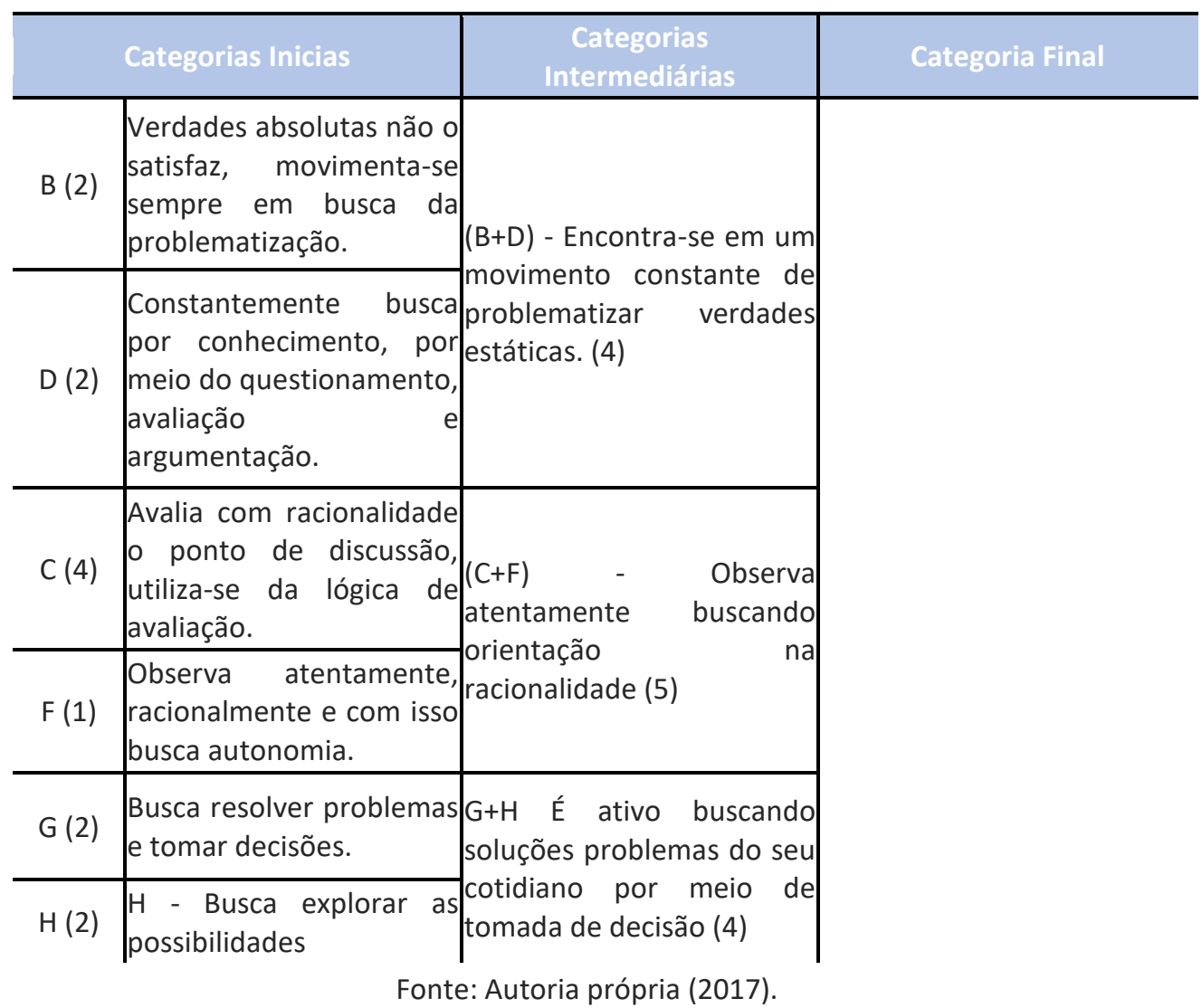

\section{O PERFIL DO PENSADOR CRÍTICO: POTÊNCIA NO PROCESSO DE DESVELAMENTO DA REALIDADE}

Não é incomum, quando questionamos noss@salun@s/professor@s em formação,formador@s de professor@se professor@s em atuação no contexto do Ensino Médio, acerca do objetivo do Ensino de Química e nos deparamos com a resposta "formar cidadãos", "formar cidadãos críticos" e/ou "formar para a cidadania". No entanto, quando ampliamos o questionamento no sentido de discutirmos que estratégias podem vir a se configurar como potencialmente úteis dentro desse objetivo, surgem propostas que não tem especificamente essa finalidade. Sendo assim, como exigirmos de nossos alunos uma formação para a vida em democracia, sem a constituição de um olhar crítico e participativo?

Precisamos compreender e problematizar nossas práticas, as incoerências e as distâncias entre o que falamos e o que fazemos. Trata-se do argumento proposto por Freire $(1996$, p.65) sobre o qual afirma que:

[...] no esforço que nos impomos para diminuir a distância entre o que dizemos e o que fazemos. Este esforço, o de diminuir a distância entre o discurso e a prática, é já uma dessas virtudes indispensáveis - a da coerência. Comumente encontramos como um dos argumentos sinalizados.

Diante desse contexto, buscamos compreender as concepções expressas por licenciand@s em Química acerca da definição do que seria pensamento crítico, buscamos delinear suas características e tecermos possíveis contribuições para o Ensino de Química. 


\title{
OLHAR E PROBLEMATIZAR A REALIDADE
}

Segundo as escritas expressas pelos licenciand@s, o pensamento crítico promove um movimento de observação atenta e crítica para a realidade, promovendo ao pensador crítico o desvelamento do contexto em que se encontra imerso, oportunizando a compreensão do que não apresenta-se explicitamente. L6 ${ }^{1}$ argumenta que o pensamento crítico promove ao sujeito um olhar questionador, no sentido de analisar e observar o mundo em que se insere, nas palavras d@licenciand@:

\begin{abstract}
Atualmente ouvimos muito falar em formar cidadãos críticos, mas como é um pensamento crítico? Quando algo acontece e queremos saber o porquê do ocorrido, como ocorreu e quem foi o culpado. Isso já é um pensamento crítico, para analisarmos bem, vamos voltar na época medieval, neste tempo tudo o que ocorria era porque Deus Pai quis assim, se alguém morria, se você nasceu pobre morreria pobre e ninguém questionava se isso era certo, com isso os que estavam no comando nessa sociedade se aproveitavam dos leigos, muitas vezes de forma cruel, com o passar do tempo isso foi mudando e começaram a questionar e viram que não era bem assim. Com isso vemos a importância do pensamento crítico, com ele aprendemos como observar o mundo que nos cerca, como ele vamos observar se o que os governantes fazem está correto e entre várias coisas. A formação de cidadãos críticos acontece nas escolas desde o ensino infantil.
\end{abstract}

Algumas questões podem ser percebidas diante da análise desta unidade de significado, primeiramente a questão de que o pensamento crítico é sinalizado como uma qualidade desenvolvida. Ou seja, ao abordar o que é pensamento crítico os licenciand@s comumente relatavam um perfil de pensador crítico. Algo que é desenvolvido, como qualidade, uma forma de olhar para a realidade na sua complexidade e problematizá-la. A segunda sinalização expressa se refere a influência que o contexto histórico e cultural exerce sobre o movimento de questionamento, frequentemente relacionado ao pensamento crítico. Intensificando o ato de questionar potencializa-se em conjunto de sociedades que rompem progressivamente com a doutrinação e determinismos.

Nesse sentido percebemos que os licenciand@s expressam a compreensão de que o pensamento crítico oportuniza ao sujeito, ou seja, uma compreensão do mundo por meio de um olhar crítico, sem alguns dos véus que nos impossibilita enxergar a realidade na qual estamos inseridos. O conceito de realidade é intensamente discutido no campo da psicanálise, no sentido de compreender a relação entre sujeito e o exterior a ele. Berger e Luckmann (2002, p. 11), definem realidade "como uma qualidade pertencente a fenômenos que reconhecemos terem um ser independente da nossa própria volição [...]".

A realidade é construída socialmente e mantém-se pela corporificação de rotinas - essência da institucionalização. Pode se subdividir em realidade objetiva, institucionalmente definida, e realidade subjetiva, apreendida na consciência individual (BERGER; LUCKMANN, 2002). A socialização configura-se como um elemento que proporciona a determinação da realidade objetiva e subjetiva, jamais é completa, os conteúdos que interioriza estão constantemente sendo desequilibrados pela realidade subjetiva. Assim, precisam ser realizados procedimentos para conservação da realidade (preservando um certo grau de simetria entre a realidade objetiva e subjetiva) (BERGER; LUCKMANN, 2002). 
Diante do exposto podemos argumentar que o pensamento crítico promove o desvelamento do olhar do sujeito proporcionando-o compreender o real sentido do contexto histórico e cultural em que está imerso. Oportuniza ao sujeito problematizar seu entorno, por meio da observação atenta e crítica. L8 apresenta essa argumentação de forma mais explícita quando define que o pensamento crítico permite ao sujeito enxergar sua posição na sociedade, observando e ouvindo diferentes pontos de vista, como pode ser observado a seguir:

o pensamento crítico nada mais é do que enxergar a sua posição na sociedade, e enxergar os outros pontos de vista que o cercam. Isso significa que, o pensador crítico tem a capacidade de se autoavaliar. Pessoas com essa característica não se prendem a uma única ideia, mas estão constantemente, observando e ouvindo os diferentes pontos de vista, antes de agir e tomar uma decisão, ou simplesmente criticar.

Observamos que a compreensão expressa pelos licenciand@s tangencia alguns dos pressupostos defendidos na teoria freireana, no sentido em que atribuem ao pensador crítico uma possibilidade de desvelamento. Quando pensamos nos conceitos de oprimido e opressor discutidos por Freire (1987) e nos processos que objetivam a transformação da realidade por meio da desalienação, podemos atribuir sentidos próximos ao expresso pelos licenciand@s quando abordam o perfil do pensador crítico.

Sobre como realizar tal desvelamento L15 argumenta que o pensador crítico questiona o mundo ao seu redor, por meio de uma observação atenta e questionadora. Nas palavras d@ licenciand@:

\footnotetext{
Na sociedade em que vivemos é de fundamental importância prepararem os alunos para questionarem o mundo ao seu redor, assim o pensamento crítico deve ser desenvolvido no aluno desde cedo, o professor tem o papel de estimular no aluno o comportamento de observador e questionador. $O$ professor deve incentivar o aluno e criticar e todo se perguntar o porquê disso ou daquilo, incitá-lo a procurar respostas e não aceitar como verdade tudo o que ele houve.
}

Não basta observar a realidade, tentar compreendê-la objetivando seu desvelamento, para tanto existe a necessidade de um olhar atento, questionador e problematizador. O questionamento vem sendo defendido como uma ferramenta essencial no processo de elaboração de estratégias que objetivem a promoção do pensamento crítico (VIEIRA; TENREIRO-VIEIRA, 2005). Algumas de suas finalidades, nesse contexto, se destinam a encorajar a participação de forma ativa dos alunos na sala de aula, desenvolver a comunicação envolvimento nas discussões (VIEIRA; TENREIRO-VIEIRA, 2005). Podemos relacionar tais fatores a uma participação efetiva na vida em uma sociedade democrática e porque não de possível transformação da realidade.

\section{QUESTIONAR VERDADES ESTÁTICAS}

Uma segunda dimensão, expressa pelos licenciand@s nas escritas dos Portfólios, compreende que ter desenvolvido o pensamento crítico implica não aceitar verdades como absolutas. Nesse contexto de discussão o pensamento crítico proporciona ao sujeito um movimento constante de problematização, 
contrapondo-se a tudo que é concebido como verdadeiro sem maior discussão do porquê.

Essa perspectiva pode ser observada na escrita do L18:

O pensamento crítico é ter uma opinião sobre o assunto a ser tratado. Não aceitar como absoluto sem nenhum questionamento isto que eu acho que é pensamento crítico. O pensamento crítico consiste em analisar e avaliar a consistência do que lhe é dito assim aderindo uma opinião própria de determinado assunto.

Essa postura questionadora, corroborada na dimensão anterior "olhar e problematizar a realidade", nos proporciona tecer discussões, novamente, sobre a influência do contexto histórico e cultural no processo de construção do conhecimento. Para tanto, podemos nos apropriar das discussões tecidas por Chauí (2000), quando discorre sobre a perspectiva construtivista de ciência e argumenta que a mesma pode ser compreendida como uma construção de modelos explicativos para a realidade e não uma representação da própria realidade. Não se espera portanto, apresentar uma verdade e sim uma verdade aproximada que pode ser corrigida, modificada, abandonada por outra mais adequada aos fenômenos.

A busca constante pelo conhecimento, por meio do questionamento, avaliação e argumentação potencializa o processo de desconstruir verdades que impossibilitam problematização. Tal compreensão é expressa por L5 em sua escrita no Portfólio:

Ter um pensamento crítico é saber receber informações, avaliar e argumentar o porquê que aquilo acontece, aconteceu ou vai acontecer, ter novas ideias e saber passar aquilo que é necessário para mudar ou melhorar alguma coisa, porém para ter esse tipo de pensamento é preciso a busca intensa pelo conhecimento.

Cabe salientar a relevância de construirmos espaços para discutirmos com nossos alunos, aspectos correlacionados a História da Ciência, sua provisoriedade, influências, imparcialidades e subjetividades. Portanto, consideramos pertinente no processo de elaboração de estratégias promotoras do pensamento crítico, oportunizar discussões acerca da História da Ciência, gnosiológicas e epistemológicas.

\section{ORIENTAR-SE PELA RACIONALIDADE NA OBSERVAÇÃO}

A observação é retratada como um elemento importante no desenvolvimento do pensamento crítico, porém não se trata de qualquer observação. A racionalidade é proposta com sentido de orientar a observação pela razão, deixando de lado, na medida do possível, a emoção. O pensador crítico observa atentamente buscando orientação na racionalidade, configura-se como uma observação ativa, que compreende o processo de não neutralidade, visando analisar as distintas variáveis envolvidas.

Não se trata de desligar-se da emoção, mas conseguir estratégias de trabalhar problematiza a questão da observação no processo de pesquisa: 
Em tempo algum pude ser um observador "acizentadamente" imparcial, o que porém, jamais me afastou de uma posição rigorosamente ética. Quem observa o faz de um certo ponto de vista, o que não situa o observador em erro. O erro na verdade não é ter um certo ponto de vista, mas absolutilizá-lo e desconhecer que, mesmo do acerto de seu ponto de vista é possível que a razão ética nem sempre esteja com ele.

Avaliar com racionalidade o ponto de discussão, utilizando-se da lógica configura-se como um outro aspecto defendido pel@s licenciand@s. L7 argumenta que o "Pensamento crítico é um julgamento propositado e reflexivo sobre o que acreditar ou o que fazer em resposta a uma observação experiência, expressão verbal, escrita ou argumentos".

Observar atentamente e de modo racional, possibilita a autonomia de ideias ao pensador crítico. Ser autônomo, no sentido de ter suas próprias compreensões, buscando minimizar as influências em que estamos constantemente sendo submetidos. O licenciando L9 apresenta essa compreensão no trecho a seguir:

O pensamento crítico é necessário para o ato reflexivo, desenvolver a capacidade de observação, autonomia de pensar, ter suas ideias. As principais características de um pensamento crítico é a curiosidade, questionando profundamente, fazendo seus próprios julgamentos e decisões, ao invés de permitir que os outros façam isso por ele.

Estamos constantemente tendo acesso, de forma rápida e fácil, a informação. Conseguir filtrar o que realmente se apresenta como confiável vem se configurando como uma exigência no contexto atual da sociedade em que estamos imersos. A prática pedagógica precisa se reorientar no sentido de instrumentalizar nossos alunos para o convívio dentro desse contexto. Behrens (2013) argumenta que o processo metodológico da prática pedagógica organizou-se, essencialmente, a partir de duas dimensões ao longo da história. A primeira ancorada no paradigma newtoniano-cartesiano, orientado por um ensino fragmentado e conservador, com foco central na reprodução do conhecimento. E uma segunda dimensão caracterizada como inovadora, com eixo central na produção do conhecimento, buscando a aproximação sujeito e objeto (BEHRENS, 2013).

\section{BUSCAR SOLUÇÕES PARA PROBLEMAS E TOMAR DECISÕES}

O pensamento crítico constitui-se pela exigência de uma postura ativa na busca por soluções de problemas provenientes do cotidiano, proporcionando um processo de tomada de decisão consciente. Ancorada por meio de um árduo movimento de análise das infinitas possibilidades de causa e efeito.

Essa dimensão é descrita pel@ licenciand@ L12 em sua escrita no Portfólio:

O pensamento crítico não se cria, mas se constrói ao longo do tempo, a característica mais forte de um crítico, seria sempre estar melhorando, criticar não pelo fato de piorar, mas sim melhorar, a crítica nos obriga a mudar, pensar e tomar atitudes sobre determinado assunto, nunca aceitar totalmente um pensamento, aceitando e discordando ao mesmo tempo, tentando entender e buscando novas ideias.

Nesse processo, a busca por explorar as possibilidades proporciona um processo de tomada de decisão de forma mais consciente. Não podemos 
argumentar que esta possa vir a ser a decisão correta, mas sim que a mesma se constituirá por meio de um processo de análise e seleção, e não mais por simples escolha aleatória. Ao discorrerem sobre o conceito de pensamento crítico Tenreiro-Vieira e Vieira argumentam que o mesmo configura-se como "um pensamento virado para a resolução em direção à ação, ou seja, é uma atividade prática" (2001, p. 27).

Sobre esse movimento de explorar possibilidades L17 tece a seguinte discussão:

Quando há em uma sala de aula um aluno crítico, você percebe que ele é uma pessoa exploradora e que tem um conhecimento, vamos falar assim, básico de muitas coisas, o que provoca dúvidas ou até mesmo conclusões em si, que faz portanto, o questionamento diante de seus colegas e seus orientadores.

Diante do exposto percebemos uma sinalização importante, destacada pel@slicenciand@s em suas escritas nos Portfólios e reverberadas por autores com larga experiência nesse contexto de investigação, a relação entre esta forma de pensar, com capacidades e disposições delimitadas em pesquisas como as propostas por Ennis (1987), onde propõe uma taxonomia², e um movimento para a ação, como é complementado por Tenreiro-Vieira e Vieira (2001).

Como argumento aglutinador, ancorado nessas quatro dimensões: olhar e problematizar a realidade; questionar verdades estáticas; orientar-se pela racionalidade na observação e; buscar soluções para problemas e tomar decisões, apresentadas até o momento podemos inferir que o pensador crítico problematiza o contexto em que se insere por meio de olhar crítico e atento. Observando com racionalidade, buscando constantemente por conhecimento e desconstruindo verdades estáticas.

\section{CONSIDERAÇÕES FINAIS}

Mediante a análise das escritas produzidas pel@s licenciand@s em seus Portfólios nos proporcionou tecer algumas compreensões, sinalizações ou mesmo pistas do conceito de pensamento crítico, sob a ótica desses sujeitos e suas articulações com o Ensino de Química. Primeiramente, percebemos que em suas escritas, quando desafiados a falar sobre o que entendiam por pensamento crítico, na ampla maioria, utilizavam uma abordagem onde um perfil de pensador crítico era exposto. Ou seja, para apresentarem o conceito de pensamento crítico, empregavam como estratégia o delineamento de uma forma de pensar e agir. No mesmo direcionamento, percebemos que ao discutir sobre o perfil do pensador crítico, em termos de capacidades e disposições, estabeleciam ações a serem realizadas. Não restringindo a forma de pensar apenas em âmbito teórico, mas delegando-se a esta forma de pensar uma atitude, ação.

A emergência dos horizontes interpretativos, possíveis diante do processo da análise das unidades de significado, escritas d@s licenciand@s nos Portfólios, nos proporcionou compreender uma potencialidade do pensamento crítico no contexto educacional. Está correlacionada a possibilidade de transformação da realidade, por mais que o desenvolvimento do pensamento crítico não tenha essa finalidade, principalmente se nos centrarmos da linha de discussão tecida no campo das pesquisas na Didática das Ciências, percebemos uma potencialidade do 
mesmo nessa linha de direcionamento. Essencialmente quando buscamos articular os pressupostos da teoria Freireana as capacidades e disposições expressas pel@slicenciand@s em suas escritas. 


\title{
Critical Thinkers' Understandings on Chemistry: A Possible Interpretive Horizon
}

\begin{abstract}
Weaimtounderstandhowteachers in training conceivetheconceptofcriticalthinking. In orderto do so, wehaveanalyzedwrittentextsproduced in a curricular componentwithfull time allocatedtoPractice as a Curricular Component. These are thefirstwritingmovementofthelicensees in the Portfolio, aninstrument for evaluatingthecomponentmentionedabove. Nineteenpaperswereelaborated, basedontheassumptionsofDiscursive Textual Analysis $\quad$ (ATD). Beforetheanalysisofthetextsemergedthe final categoryentitled "The profile ofthecriticalthinker: power in theprocessofunveilingof reality", in whichthecriticalthinkerisassignedtheabilityto problematize thecontext in which it isinsertedthrough a criticalandattentive look. Observingwithrationality, constantlyseeking for knowledgeanddeconstructingstatictruths.

KEYWORDS:Teachingmaterials. QualitativeReasoning. Science Teaching.
\end{abstract}




\section{AGRADECIMENTOS}

A CAPES pelo apoio financeiro e aos licenciand@s que colaboraram com a pesquisa.

\section{NOTAS}

1 Com intuito de preservar a identidade d@slicenciand@s colaboradores desta pesquisa optamos pelo uso desta codificação.

2 A taxonomia proposta por Ennis (1987), adaptada por (Vieira; Tenreiro-Vieira, 2005), permite a identificação das capacidades de pensamento crítico necessárias para o desenvolvimento de determinadas atividades e define o pensamento crítico como uma forma de pensar que envolve reflexão coerente com o objetivo de compreender sobre o que acreditar e fazer, sendo esse processo constituído por disposições e capacidades específicas. Em sua definição operacional envolve quatorze disposições e cinco capacidades com diversos desdobramentos e significados (Vieira; Tenreiro-Vieira, 2005). 


\section{REFERÊNCIAS}

ALMEIDA, E.C.S; ANDRADE, J.M.; BRASILINO, M.G.A. e FONSECA, M.G. A contribuição do PIBID/UFPB na formação inicial de alunos de licenciatura em química. In: ENCONTRO NACIONAL DE ENSINO DE QUÍMICA, 15. Anais. Brasília, 2010.

ALMEIDA, P. C. A.; BIAJONE, J. Saberes docentes e formação inicial de professores: implicações e desafios para as propostas de formação. Educação e Pesquisa, São Paulo, v.33, n.2, p.281-295, 2007.

ARAUJO, E. S; MOURA, M. O. Contribuições da teoria histórico cultural à pesquisa qualitativa sobre formação docente. In: PIMENTA, S. G; FRANCO, M. A. S. Pesquisa em educação: possibilidades investigativas/formativas da pesquisaação. São Paulo: Loyola, 2008, p. 75-101.

BEHRENS, M. A. O paradigma emergente e a prática pedagógica. Petrópolis, RJ: 6. ed. Vozes, 2013.

BERGER, P.; LUCKMANN, T. A construção social da realidade. Petrópolis: Vozes, 1985.

BORGES, C.; TARDIF, M. Apresentação. Educação e Sociedade, São Paulo, v. 22, n. 74, p. 11-26, abr. 2001.

CHAUÍ, M. Convite a Filosofia. São Paulo: Ed. Ática, 2000.

ENNIS, R. H. A taxonomy of critical thinking dispositions and habilities. In J. B. Baron e R. J Sternberg (Eds.). Teaching Thinking skills: Theory and practice. New York: W. H. Freeman and Company, 1987.

. Critical thinking dispositions: Their nature and assessability. Informal Logic.Vol.18, p. 165-182, 1996.

FREIRE, Paulo. Pedagogia da Autonomia: saberes necessários à prática educativa. São Paulo, Ed Paz e Terra, 1996.

FREIRE, Paulo. Pedagogia do oprimido. Ed Paz e Terra, 23 ed, Rio de Janeiro, 1987. 
HALPERN, D. F. Thought and Knowledge - An introduction to critical thinking. New Jersey, Editora Lawrence Erlbaum Associates, 1989.

HALPERN, D. F. Teaching critical thinking for transfer across domains Dispositions, skills, structure training, and metacognitive monitoring. American Psycologist, 53:1, 449-455, 1998.

MORAES, R.; GALIAZZI, M.C. Análise Textual Discursiva. ljuí: Ed. Unijuí, 2011.

PAREDES, G. G. O.; GUIMARÃES, O. M. Compreensões e Significados sobre o PIBID para a Melhoria da Formação de Professores de Biologia, Física e Química. Química Nova na Escola, v. 34, p. 266-277, 2012.

PAUL, R; ELDER, L. The miniature guide to Critical Thinking - Concepts and tools. The Foundation for Critical Thinking, $4^{\circ}$ ed; 2006.

PAUL, R; ELDER, L. The thinker's guide to the nature and functions of Critical and Creative thinking. The Foundation for CriticalThinking, 1ed; 2008.

RODRIGUES, Maria ÂngelaPerpétua. Análise de práticas e de necessidades de formação. Lisboa: Colibri, 2006.

SOARES, S. R.; CUNHA, M. I. Formação do Professor: a docência universitária em busca de legitimidade, Scielo Books, Editora da Universidade Federal da Bahia, Salvador, 2010.

SOUZA, R. S; GALIAZZI, M.C. Compreensões Acerca da Hermenêutica na Análise Textual Discursiva: Marcas Teórico-Metodológicas à Investigação. Contexto e Educação. Editora Unijuí Ano 31 no 100 Set./Dez. 2016.

SZABO, Z. \& SCHWARTZ, J. Métodos de aprendizagem para formação de professores: o uso de discussões on-line para melhorar o pensamento crítico. Tecnologia, Pedagogia e educação, 20: 1, 79-94, 2011.

TENREIRO-VIEIRA, C. O pensamento crítico na Educação científica.Lisboa, Instituto Piaget, 2000.

TENREIRO-VIEIRA, C.; VIEIRA, R. M. Promover o pensamento crítico dos alunos: propostas concretas para sala de aula. Porto, Portugal: Porto editora, 2001. 
TENREIRO-VIEIRA, C. Produção e avaliação de actividades de aprendizagem de ciências para promover o pensamento crítico dos alunos. Revista Iberoamericana de Educación, vol 33, no 6, p. 1-17, 2004.

VIEIRA, R. M; TENREIRO-VIEIRA, C. Práticas didático-pedagógicas de ciências: estratégias de ensino/aprendizagem promotoras do pensamento crítico. Saber \& Educar, 20, 34-41, 2015.

VIEIRA, R. M; TENREIRO-VIEIRA, C. Estratégias de ensino/aprendizagem: o questionamento promotor do pensamento crítico. Lisboa, Instituto Piaget, 2005.

VILLAS BOAS, B.M. de F. Portfólio, avaliação e trabalho pedagógico. Coleção Magistério: Formação e Trabalho Pedagógico. Campinas, SP: Editora Papirus, 2004.

Recebido: 29mai. 2017

Aprovado: 21 jul. 2017

DOI: 10.3895/actio.v2n1.6751

Como citar:

CALIXTO, V. dos S.; BORDONI, A. J.; TAKAHASHI, D. A. G.; KIOURANIS, N. M. M.; SILVEIRA, M. P. da Compreensões de licenciand@s em Química acerca do Pensamento Crítico: um possível horizonte interpretativo. ACTIO, Curitiba, v. 2, n. 1, p. 184-203, jan./jul. 2017. Disponível em:

$<$ https://periodicos.utfpr.edu.br/actio>. Acesso em: XXX.

Correspondência:

Vivian dos Santos Calixto

UGGD Rodovia Dourados - Itahum, Km 12, Caixa Postal - 533, CEP: 79804-970 - Dourados/MS, Brasil. Direito autoral: Este artigo está licenciado sob os termos da Licença CreativeCommons-Atribuição 4.0 Internacional.

(c) (1) 